SAADI RADCLIFFE

\title{
SOFTWARE PATENTS AS SUCH: SOFTWARE PATENTABILITY IN NEW ZEALAND UNDER THE PATENTS BILL
}

Submitted for the LLB (Honours) Degree

\author{
Faculty of Law
}

Victoria University of Wellington

2013 


\section{Contents}

I Introduction 4

II Previous New Zealand Law on Software Patents

A The Patents Act 1953

$B$ Case law concerning applications for computer software patents 5

III The Progression of the Patents Bill 6

A The initial Bill 6

$B$ The Commerce Select Committee report and the exclusion of software 7

C Supplementary Order Paper No 120 - new clause 10A 9

IV Analysis of the statutory interpretation of "as such" - 10

Supplementary Order Paper No 120 - New Clause 10A

A Dictionary meaning and ordinary usage 10

B Statutory context 11

$\begin{array}{ll}\text { C Purpose } & 12\end{array}$

D The European approach to "as such" 14

1 Critique of the European approach 15

E The United Kingdom approach to "as such” 16

$\begin{array}{ll}F \text { A New Zealand Approach } & 18\end{array}$

$V$ Analysis of the statutory interpretation of "as such" - 20

Supplementary Order Paper No 237 - Amended Clause 10A

VI Consistency with the Agreement on Trade-Related Aspects of 22

Intellectual Property Rights

A Is software technology?

VII Problems with the new Clause 10A 23

$\begin{array}{ll}\text { A Market incentives } & 24\end{array}$

B Distributed systems $\quad 25$

VIII Conclusion 26

$\begin{array}{ll}\text { IX Bibliography } & 28\end{array}$ 


\section{Abstract}

This paper examines the patentability of software under the Patents Bill. It attempts to determine how a New Zealand court will interpret the provisions of the Patents Bill that relate to the exclusion of software, and to what extent the "as such" exclusion will apply. It does this by looking at principles of statutory interpretation and the relevant English and European case law on the matter. It concludes that a New Zealand court will interpret the provision in accordance with UK precedent to give it a narrower interpretation than that given in Europe. The paper then examines the consistency of the provisions with the relevant international law before discussing some problems that may arise regarding market incentives and distributed systems. It proposes that the provision strikes an appropriate balance between protection and innovation in line with Parliament's intent.

\section{Key Words}

software patents; Patents Bill; as such; statutory interpretation 


\section{Introduction}

Once the sole domain of cellar-dwelling boffins, computer software has leapt into the public sphere in recent years. The proliferation of mobile devices has opened up whole new markets for developers who sell their "apps" through online marketplaces. The internet has shaped our lives in many ways and even software is not immune to evolution. Whereas once all software was stored and run locally, today it is just as likely to be distributed in the cloud.

Previously, the law in New Zealand permitted the granting of software patents. But with the presentation of the Patents Bill, Parliament was given the opportunity to re-examine this position. The purpose of this paper is to examine and determine how a New Zealand court will interpret the provisions of the Patents Bill that relate to the exclusion of software and to what extent the exclusion will apply.

The first part of this paper describes the old law under the Patents Act 1953 and then examines the progress of the Patents Bill. It then analyses the meaning of the exclusion provision with recourse to statutory interpretation techniques and an analysis of English and European case law. It concludes that Parliament's intent is in alignment with the approach in the UK and that this interpretation is also consistent with New Zealand's international obligations.

The final part of the paper explores implications that the law may have for market incentives and distributed systems. The dynamism of the law was markedly apparent in the preparation of this paper. Adjustments in approach and argument had to be made as the Patents Bill made its way through the legislative process. The introduction of supplementary order papers amending parts of the Patents Bill relevant to this paper necessitated new analyses. Indeed the Patents Bill has now become the Patents Act 2013. This paper analyses both of the supplementary order papers, the second of which has now become law. It then concludes that the new Patents Act 2013, has managed to strike an appropriate balance between protection and innovation. It is unlikely that this law will have a chilling effect on technological innovation in New Zealand. 


\section{Previous New Zealand Law on Software Patents}

\section{A The Patents Act 1953}

Prior to the enactment of the Patents Act 2013, regulation of patents in New Zealand was achieved through the Patents Act 1953. Patent law represents an attempt to incentivise innovation and development by providing protection through the granting of proprietary rights. ${ }^{1}$ The ideological basis driving this position seeks to encourage technological invention whilst discouraging trade secrets. ${ }^{2}$ In New Zealand the public disclosure of patents is rewarded with a 20 -year monopoly. ${ }^{3}$ The subject of a patent application must satisfy the statutory definition of "invention". ${ }^{4}$ Patents are examined by the Intellectual Property Office of New Zealand (IPONZ) to determine whether the invention is novel and that it satisfies other conditions for grant of a patent and may be opposed by thirdparties. ${ }^{5}$ Patents may also be refused by statutory bar "if it appears to the Commissioner in the case of any application for a patent that the use of the invention in respect of which the application is made would be contrary to morality". 6 There is no subject matter exclusion for software in the Patents Act and the body of patent applications shows that computer software may be patented in New Zealand. ${ }^{7}$

\section{$B$ Case law concerning applications for computer software patents}

The issue of software patentability was addressed in Hughes Aircraft ${ }^{8}$ and the affirmative decision in that application laid the basis for software patentability. ${ }^{9}$ That case concerned the application for a computer controlled process that determined the conflict alert status of pairs of aircraft by measuring their position and velocity. ${ }^{10}$ The computer system evaluated rates of convergence and height separation through measuring the changes in position and velocity of aircraft pairs. ${ }^{11}$ A conflict alert status would be established if the

\footnotetext{
${ }^{1}$ Susy Frankel Intellectual Property Law in New Zealand (2 ${ }^{\text {nd }}$ ed, LexisNexis, Wellington, 2011) at 391.

${ }^{2}$ Frankel, above n 1, at 392.

${ }^{3}$ Patents Act 1953, s 30(3) and Patents Act 2013, s 30(3).

${ }^{4}$ Patents Act 1953, ss 2 and 7(1).

${ }^{5}$ Frankel, above n 1, at 393.

${ }^{6}$ Patents Act 1953, s 17(1).

${ }^{7}$ Frankel, above n 1, at 801 .

${ }^{8}$ Hughes Aircraft Application Patent Office, Patent Application Nos 221147, 233797 and 233798, 3 May 1995.

${ }^{9}$ Frankel, above n 1, at 808 .

${ }^{10}$ Hughes, above n 8 , at 3 .

11 At 3.
} 
resulting data met a set of five conditions. ${ }^{12}$ The system aided air traffic controllers by automating part of their operations thereby reducing human error and increasing aviation safety. Commissioner Popplewell noted that the only relevant case was the decision in Clark's ${ }^{13}$ and that despite the review of case law from other jurisdictions, there was still considerable doubt over the patentability of software. ${ }^{14}$ The Commissioner felt compelled to follow the principles laid down in $I B M^{15}$ by the Australian Federal Court. ${ }^{16}$ The test derived from that case was whether the invention claimed involved the production of some commercially useful effect. ${ }^{17}$ Specifically, the Commissioner held that: ${ }^{18}$

c) A claim to a mathematical algorithm when used in a computer is patentable so long as a commercially useful effect is produced.

$\cdots$

The Commissioner applied this test and decided that the claims defined a method which produced a commercially useful effect, that effect being an improvement in air traffic control through the prevention of mid-air collisions. ${ }^{19}$ This decision has resulted in the subsequent granting of patents in New Zealand. ${ }^{20}$

\section{The Progression of the Patents Bill}

\section{A The initial bill}

Patent law was due for an overhaul in New Zealand and Parliament was given the opportunity for reform with the introduction of the Patents Bill. ${ }^{21}$ The general policy statement of the Patents Bill states that it is to: ${ }^{22}$

...update New Zealand's patent regime to ensure that it continues to provide an appropriate balance between providing adequate incentives for innovation and 
technology transfer while ensuring that the interests of the public and the interests of Māori in their traditional knowledge and indigenous plants and animals are protected.

There was also concern that the threshold for granting patents in New Zealand was too low and that rights granted in New Zealand were broader than rights granted in other countries for the same invention. ${ }^{23}$ This could have a chilling effect on innovation and inhibit growth and the productivity of exports.

The Patents Bill added to the existing exclusion on the grounds of public morality contained in the Patents $\mathrm{Act}^{24}$ by including patentability exclusions for human beings and biological processes for their generation, surgical or therapeutic treatments, diagnosis methods and plant varieties. ${ }^{25}$ The Patents Bill was noticeably silent on the topic of software patents.

\section{$B$ The Commerce Select Committee report and the exclusion of software}

The Commerce Select Committee recommended the addition of software to the list of exclusions to the Patents Bill of inventions that may not be patented by providing that "a computer program is not a patentable invention". ${ }^{26}$ The Select Committee was persuaded by arguments that software merely builds on existing software and that affording patent protection would stifle innovation and competition. ${ }^{27}$ The main proponents of this argument came from the open source software community, in particular the New Zealand Open Source Society (NZOSS). ${ }^{28}$ Open source software is software that has released its human readable source code so that developers may add to it and develop it as they choose. Advocates of the open source model argue that this leads to greater innovation and a greater common stock of technology. ${ }^{29}$ The NZOSS also adduced arguments that considered the creation of software to be a form of creative expression and drew an analogy to the patenting of plot lines in a book. ${ }^{30}$ This argument gives implicit approval

\footnotetext{
${ }^{23}$ At 2.

${ }^{24}$ Patents Act 1953, s 17(1).

${ }^{25}$ Patents Bill 2008 (235-1), cl 15.

${ }^{26}$ Patents Bill 2008 (235-2), cl 15(3A).

${ }^{27}$ Patents Bill 2008 (235-2) (select committee report) at 5.

${ }^{28}$ New Zealand Open Source Society "Submission on the Patent Bill 235-1 before the Commerce Committee".

${ }^{29}$ InternetNZ "Submission to the Commerce Committee on the Patents Bill (235-1) at 16.

${ }^{30}$ New Zealand Open Source Society, above n 28, at 1.
} 
to an existing intellectual property protection mechanism, namely copyright law, where computer programs are afforded protection as literary works. ${ }^{31}$

A final concern was the effect that software patents would have on the prevalence of 'patent trolls'. ${ }^{32}$ A patent troll is an organisation that purchases patents with the intention of negotiating licensing agreements with companies that manufacture products using that technology. ${ }^{33}$ Patent searches may be readily performed for a large manufacturer of specific products. However the complexity of software and the fact that it is often written by bedroom programmers and small firms with limited resources, means that it may not be feasible to undertake searches in order to check for infringement. ${ }^{34}$ In any event, the cost of doing business rises with the increased transaction costs associated with patent searching. This may also remove some of the momentum attached to the development of new and innovative products, such as those at the cutting edge of technology, thereby having a chilling effect on this area of commerce.

The possibility of the software exclusion under $\mathrm{cl} 15$ was predicted by various submissions prior to the Select Committee report, including one made on behalf of Fisher \& Paykel. ${ }^{35}$ In its submission, Fisher \& Paykel specifically supported the "absence of 'computer software related inventions' from the listed exclusions". ${ }^{36}$ Fisher \& Paykel is a manufacturer of whiteware and a significant proportion of their inventions are software related inventions. ${ }^{37}$ Their submission gave the main example of embedded software, that is, software residing in microchips on the circuit boards of the appliance. Embedded software is crucial to the functioning of the microprocessors which control elements of the motors such as the "speed, direction, acceleration, deceleration and torque". 38 The majority of Fisher \& Paykel's competitors are based abroad and so patent protection is sought in many other countries, although company policy seeks to obtain patents in New Zealand also. ${ }^{39}$ Additionally, Fisher \& Paykel showed the shared concern that the threshold for granting patents in New Zealand was too low and that foreign competitors

\footnotetext{
${ }^{31}$ Copyright Act 1994, ss 2, 14 and 16.

${ }^{32}$ New Zealand Open Source Society, above n 28, at 9.

33 At 9 .

34 At 9.

35 Fisher \& Paykel Appliances Limited "Submission on the Patents Bill 2009 to the Commerce Committee".

${ }^{36}$ At 4.

${ }^{37}$ At 5 .

${ }^{38}$ At 5 .

${ }^{39}$ At 3 .
} 
might be able to obtain patents in New Zealand that they might not be able to obtain in their own and other countries. ${ }^{40}$ This could have the undesirable result of Fisher \& Paykel being precluded from employing technology in New Zealand on the grounds of patent infringement, which could be used with impunity abroad. The overzealous use of the patent system could disadvantage New Zealand companies in their own backyard to the point of even removing them as market participants.

In a nod to Fisher \& Paykel, the Select Committee noted in its report that they were aware of New Zealand companies that had invested significantly in a number of softwarerelated inventions involving embedded software. ${ }^{41}$ The Select Committee considered the importance of allowing software patents in this area of endeavour but stated that: ${ }^{42}$

After careful consideration we concluded that developing a clear and definitive distinction between embedded and other types of software is not a simple matter; and that for the sake of clarity, a simple approach would be best. We received advice that our recommendation to include computer programs among the inventions that may not be patented would be unlikely to prevent the granting of patents for inventions involving embedded software.

Overall, the report indicated support for the statutory exclusion and a preference for a carve-out from that exclusion for embedded software but questioned whether this would be practicable. ${ }^{43}$ The Select Committee then threw the ball to IPONZ recommending that they develop guidelines for inventions containing embedded software. ${ }^{44}$

\section{Supplementary Order Paper No 120 - new clause 10A}

Supplementary Order Paper 120 introduced what was arguably the most contentious amendment to the Patents Bill. This introduced a new cl 10A the relevant part of which read: 45

10A Computer programs

(1) A computer program is not an invention for the purposes of this Act.

\footnotetext{
40 At 3.

${ }^{41}$ Patents Bill 2008 (235-2) (select committee report) at 6.

42 At 6.

${ }^{43}$ At 6.

${ }^{44}$ At 6.

${ }^{45}$ Supplementary Order Paper 2012 (120) Patents Bill 2008 (235-2) at 1.
} 
(2) Subsection (1) prevents anything from being an invention for the purposes of this Act only to the extent that a patent or an application relates to a computer program as such.

The accompanying explanatory note stated that $\mathrm{cl} 10 \mathrm{~A}$ was to replace $\mathrm{cl} 15(3 \mathrm{~A})$ and that rather than excluding computer programs from being a patentable invention, the new clause would clarify the law by preventing anything from being an invention only to the extent that a patent relates to a computer program as such. ${ }^{46}$ The motivation behind this change came from the aforementioned comments in the Select Committee's report. It was an attempt to effect a carve-out for embedded software.

\section{Analysis of the statutory interpretation of "as such" - Supplementary Order Paper No 120 - New Clause $10 \mathrm{~A}$}

The desire may have been for a clarification of the law but the effect was anything but. The legal issue raised is what meaning should a New Zealand court ascribe to the words "as such"? In New Zealand the meaning of an enactment must be ascertained from its text and in light of its purpose. ${ }^{47}$ Interpretive aids available to the courts include the dictionary meaning, ordinary usage, statutory context and the purpose of the legislation.

\section{A Dictionary meaning and ordinary usage}

The natural starting point for the analysis of the meaning of "as such" is the dictionary meaning and ordinary usage. The Concise Oxford English Dictionary defines "as such" as meaning "in the exact sense of the word". ${ }^{48}$ This implies a limitation where the application relates to a computer program in the exact sense of the word. This requires an analysis of just what exactly a computer program is. If the exact sense of the word can be determined, then supposedly so too may the scope of the phrase "as such". Webster's New World Dictionary defines "as such" as meaning "in itself". ${ }^{49}$ This points to a similar analysis, if the definition of 'computer program' can be determined, that is the thing 'in itself', then so too can the scope of the limitation. The bounds of 'computer program' will circumscribe the extent to which an application can relate to that program, and to that extent it will not be an invention.

\footnotetext{
${ }^{46}$ Supplementary Order Paper 2012 (120) Patents Bill 2008 (235-2) (explanatory note) at 19.

${ }^{47}$ Interpretation Act 1999, s 5(1).

${ }^{48}$ Concise Oxford English Dictionary ( $11^{\text {th }}$ ed revised, 2009) at 1439.

${ }^{49}$ Webster's New World Dictionary ( $3^{\text {rd }}$ college ed, 1991) at 1337.
} 
A computer program can be conceptualised in different ways. It may be viewed as human readable source code, as compiled object code, or at its most fundamental level, a series of binary digits. Appending the words "as such" to any of these conceptions should not necessarily produce inconsistencies in meaning in ordinary usage. The problem with this approach is that software is, inherently intangible. It may be expressed in tangible forms - on paper as source code, in chips as binary digits, as ephemeral signals along copper wires - but by itself it has no meaning or existence. It only gains this through its interaction with other objects, namely hardware, and the results that it produces. A computer program must be run on a computer for it has no meaning alone. The enquiry must then proceed on a footing that considers the effect that the software has, which may be equivalently viewed as its contribution. This raises further questions regarding the nature or proximity of the effect or contribution. These questions cannot be answered by reference to the wording alone. If this somewhat metaphysical riff is accepted then, an analysis based solely on the dictionary or ordinary meaning collapses, necessitating the assistance of other interpretive techniques.

\section{B Statutory context}

The statutory context may shed more light on the meaning of 'as such'. Context is vital as most words have several shades of meaning. ${ }^{50}$ Clause 15 provides for other exclusions to patentability. ${ }^{51}$ The sub-clauses cover human beings and biological processes, methods of treatment of humans by surgery or therapy, methods of diagnosis and plant varieties. Appended to each of these sub-clauses are the words "is not a patentable invention.",52 The choice of language is strong and suggests that Parliament intended to exclude this matter in its entirety. The absence of the words "as such" removes the need for an enquiry into the inherency of the subject-matter as discussed above. The enquiry is also freed from a consideration based on tangibility. Since the two phrases cannot mean the same thing, the meaning ascribed to 'as such' must be narrower than the meaning given to 'is not a patentable invention'. However, the language does not enunciate clearly how narrow this is to be interpreted.

\footnotetext{
${ }^{50}$ Legislation Advisory Committee Guidelines on Process \& Content of Legislation (2000) at [3A.1.2].

${ }^{51}$ Patents Bill 2008 (235-2), cl 15.

${ }^{52}$ Clause 15.
} 
Clause 14 excludes from patentability, inventions that are contrary to public order or morality. ${ }^{53}$ The drafting suggests a partial limitation to an exclusion from patentability: ${ }^{54}$

(1) An invention is not a patentable invention if the commercial exploitation of the invention, so far as claimed in the claim, is contrary to...public order...or...morality.

The focus here though, is on the commercial exploitation of the invention, or its use. It suggests a limitation on the exploitation of the invention but not on the subject-matter that makes up the invention. It is therefore of limited use to the contextual analysis.

The surrounding words in $\mathrm{cl} 10 \mathrm{~A}(2)$, "to the extent that", indicate an apportionment exercise may be performed when applying the section. Parliament must have contemplated the existence of inventions comprised of various components, one or more of which may involve a computer program. Those components, or to use the statutory language, "anything" not relating to computer software may form the basis of a valid patent. Parliament must have turned its mind to the possibility of inventions, which in part make some use of computer programs. It follows that Parliament must have intended some form of patent protection for these inventions albeit one limited by an apportionment exercise. This suggests a spectrum of inventions, anchored at one end by those inventions absent of any computer software component, and at the other by those consisting solely of a computer program. Those inventions devoid of any software component do not fall within the section and are of no use to the issue. Those at the other end consist solely of software, and prima facie appear to be caught by the section and excluded as inventions. However the same problems with analysis encountered above present themselves again. Computer programs are meaningless in isolation - their interaction with other objects is relevant. Applications for inventions lying somewhere between these two points gain little from the preceding analysis.

\section{Purpose}

The purpose of the Act or a provision within it, may be discovered from extrinsic material such as committee reports. ${ }^{55}$ As noted by the Court of Appeal in Frucor Beverages Ltd $v$ Rio Beverages Ltd, the attraction may be to find the literal meaning of a

\footnotetext{
${ }^{53}$ Clause 14.

${ }^{54}$ Clause 14.

${ }^{55}$ Legislation Advisory Committee, above n 50, at [3A.1.2].
} 
statutory provision but care must be taken so that an intent is not attributed to Parliament that was not its intent. ${ }^{56}$

The Bill sought to strike the balance between adequate incentives for innovation and the protection of the public interest. ${ }^{57}$ Concern was also shown that patent rights granted in New Zealand were broader than those granted abroad for the same invention, ${ }^{58}$ something that Fisher \& Paykel was also wary of in their submission. This points to a restrictive meaning of "as such".

The explanatory note accompanying Supplementary Order Paper 120 effectively restates the wording of the provision and adds little to the discussion. ${ }^{59}$ The desire to make "the approach more consistent with overseas precedents" is mentioned and this must be taken as a reference to provisions containing the phrase "as such" as enacted in Europe and the UK. ${ }^{60}$ However as will be shown later, the interpretation of these words and their application to the facts, has yielded some inconsistent results. The note goes on to imply an intention to achieve clarity in the law by affirming that only computer programs themselves are ineligible for patent protection. ${ }^{61}$

A further statement reveals the intention that a patent "may still be granted for an invention that meets all of the criteria of patentability...despite the fact that the relevant invention involves a computer program in some respect." ${ }^{2}$ This explanation can be read as meaning that the purpose of the provision is to exclude computer programs from patentability but if an invention includes a computer program, a patent may still be granted. Once again, a sliding scale may be established. If the enquiry is based on composition, at one end is the piece of pure software at the other is the invention that has a fractional amount of software in it. However, as discussed previously software has no real meaning by itself. So the question may also be posed as relating to the contribution of the software to the invention, or of the technical effect that the software has. The overarching purpose of the provision is clear, that is, the exclusion of software from patentability. However the exact scope of this exclusion remains unclear.

\footnotetext{
${ }^{56}$ Frucor Beverages Ltd v Rio Beverages Ltd [2001] 2 NZLR 604 (CA) at [27] per Thomas J.

${ }^{57}$ Patents Bill 2008 (235-1) (explanatory note) at 2.

${ }^{58}$ At 2 .

${ }^{59}$ Supplementary Order Paper 2012 (120) Patents Bill 2008 (235-2) (explanatory note) at 19.

${ }^{60}$ At 19.

${ }^{61}$ At 19.

${ }^{62}$ At 20.
} 
There is no previous law relating to software patents and so there is a complete absence of any New Zealand jurisprudence on the point. However courts may look towards other jurisdictions to help them ascertain the meaning of provisions which may guide their interpretation. The relevant jurisdictions are Europe and the UK both of which use the words "as such" in relation to software patents. Consequently a substantial corpus of law has been developed on the interpretation and application of these words. The interpretation of statutory provisions may be assisted with this judicial gloss.

\section{The European approach to "as such"}

The European Patent Office (the EPO) is responsible for the examination and granting of patents in Europe. The relevant law is contained in the European Patent Convention (the $\mathrm{EPC}):^{63}$

(2) The following in particular shall not be regarded as inventions within the meaning of paragraph 1 :

$\cdots$

(c) schemes, rules and methods for performing mental acts, playing games or doing business, and programs for computers;

(3) Paragraph 2 shall exclude the patentability of the subject-matter or activities referred to therein only to the extent to which a European patent application or European patent relates to such subject-matter or activities as such.

Therefore a court is tasked with interpreting the scope of the exclusion given by the words "as such".

The decision of the Technical Board of Appeal in Re Vicom's Application ${ }^{64}$ paved the way for the patenting of software in Europe. That case involved the digital filtering of a stored image represented by a two-dimensional array of numbers. The Board held that: ${ }^{65}$

... a claim directed to a technical process which process is carried out under the control of a program (be this implemented in hardware or software) cannot be regarded as relating to a computer program as such within the meaning of Article

\footnotetext{
${ }^{63}$ Convention on the Grant of European Patents 1973, art 52.

${ }^{64}$ Re Vicom's Application [1987] T 208/84 (Official Journal of the European Patent Office) at 14.

${ }^{65}$ At 20.
} 
$52(3) \ldots$ as it is the application of the program for determining the sequence of steps in the process for which in effect protection is sought. Consequently such a claim is allowable under Article 52(2)(c) and (3)...

This particular finding is referred to in the literature as the "technical effect doctrine". 66 The Board did not provide strict clarity on what constituted a "technical effect" but was satisfied that some physical matter must be affected ${ }^{67}$ The doctrine was stretched in $R e$ IBM's Application ${ }^{68}$ to include the patenting of a computer program that controlled the appearance of windows on a display screen. ${ }^{69}$ This was a remarkable extension of Vicom's Application. If a physical effect was still required, it was satisfied by the appearance of windows on a display screen. This required no specialised hardware and was effectively a patent over a computer program which caused the technical effect of a change in display. The Board gave a wide interpretation to the scope of patentability by giving the scope of the exclusion such a narrow interpretation.

\section{Critique of the European approach}

It is hard to imagine that a New Zealand court would favour an approach that yielded the result in Re IBM's Application. The Board of Appeal considered the case as turning on the definition of "technical character", ${ }^{70}$ following their determination that exclusions for patentability of computer programs as such, would apply where the programs were "mere abstract creations, lacking in technical character." character must lie outside of the program and that it could not be in the physical modifications of the hardware, for instance the electrical currents produced. ${ }^{72}$ These modifications were common to all computer programs and so could not be of assistance in distinguishing computer programs with a technical character from computer programs as such. ${ }^{73}$ The technical character is to be found in the further effects deriving from the execution of the program's instructions. ${ }^{74}$

\footnotetext{
${ }^{66}$ Frankel, above $\mathrm{n} 1$, at 805 .

${ }^{67}$ Alfred P. Meijboom "New Developments Regarding the Patentability of Software-Related Inventions in Europe" (1990) 72 JPTOS 583 at 583.

${ }^{68}$ Re IBM's Application [1999] RPC 861 (European Patent Office Technical Board of Appeal).

${ }^{69}$ Frankel, above $\mathrm{n} 1$, at 806.

${ }^{70} \operatorname{Re} I B M$, above n 68, at [5.5].

${ }^{71}$ At [5.2].

${ }^{72}$ At [6.2].

${ }^{73}$ At [6.3].

${ }^{74}$ At [6.4].
} 
The further technical effect in this case is the drawing of windows on a computer screen. In light of the Board's elaborate and technical approach, it can equally be said that the drawing of windows on a screen is just the type of physical modification of hardware that the Board said was insufficient to be considered as a technical effect. The rendering of windows, at the time of the case, is almost certainly the result of an electrical charge striking an element of phosphor on a display screen, a wholly common use of hardware. If this were the test adopted by a New Zealand court, the threshold for software patents, assuming they satisfied the other patentability criteria, would be very low and in direct opposition to the policy statements in the Bill. ${ }^{75}$

\section{E The United Kingdom approach to "as such"}

The UK gives effect to the European Patent Convention through the Patents Act $1977,{ }^{76}$ the wording of which is almost identical to the EPC. The leading case in this jurisdiction is Aerotel Ltd v Telco Holdings Ltd and Macrossan's Patent Application. ${ }^{77}$ These cases were heard together as they both sought to answer the question of excludability of subject matter from patentability.

The facts of Aerotel dealt with a pre-paid telephone system that allowed users to place calls from any phone. This is the type of system that enables calling card businesses to operate. Macrossan's Application related to a system that automatically generated the necessary documents for the registration and incorporation of a company.

Jacob LJ examined the various judgments of the EPO Boards of Appeal and whilst being careful not to lay criticism at the foot of any particular Board, noted that there were at least four differing points of view held by various Boards of Appeal, in the body of decisions surveyed on the point. ${ }^{78}$

Jacob LJ recognised three main approaches made by the EPO Boards of Appeal in the case law, the contribution approach, the technical effect approach and the "any hardware" approach. ${ }^{79}$ The contribution approach would reject applications where the inventive step

\footnotetext{
${ }^{75}$ Patents Bill 2008 (235-1) (explanatory note) at 2.

${ }^{76}$ Patents Act 1977 (UK), s 1(2).

${ }^{77}$ Aerotel Ltd v Telco Holdings Ltd and Macrossan's Patent Application [2006] EWCA Civ 1371.

${ }^{78}$ At [25].

${ }^{79}$ Aerotel, above n 77, at [26].
} 
resides only in the contribution of excluded matter, the technical effect approach would reject those inventions that do not make a technical contribution to the known art, and the "any hardware" approach would decline to apply the exclusion so long as the claim involved the use of a piece of physical hardware irrespective of how mundane. ${ }^{80}$

Jacob LJ then went on to examine the appropriateness of the four-step test laid down in case law and subsequently approved and adopted it for use in the instant case: ${ }^{81}$

(1) properly construe the claim

(2) identify the actual contribution;

(3) ask whether it falls solely within the excluded subject matter;

(4) check whether the actual or alleged contribution is actually technical in nature.

For the Aerotel appeal, Jacob LJ found that the test was satisfied but for Macrossan, it was not. In determining the contribution, Jacob LJ found that it was to provide a computer program which can be used to carry out the method. ${ }^{82}$ The hardware used was held to be standard and not part of the contribution and the contribution lay solely in the excluded matter. ${ }^{83}$ Finally the contribution was not held to be technical beyond the mere fact of running a computer program. ${ }^{84}$

The law advanced a further step in the Symbian Ltd $v$ Comptroller General of Patents. ${ }^{85}$ That case dealt with software that improved the run-time dynamic linking of libraries (DLLs) in a computer, which in turn sped up the entire operation of the computer. A shallow application of the relevant law may have resulted in an exclusion from patentability. However, in a rather exhaustive exploration of the UK and EPO case law, Lord Neuberger of Abbotsbury applied the four-step test in Aerotel to reach an affirmative answer. Significantly, His Lordship found that notwithstanding that the invention consisted of nothing but software, it nevertheless satisfied the third step. It did not fall solely with the excluded subject matter "because it has the knock-on effect of the computer working better as a matter of practical reality." 86

\footnotetext{
${ }^{80}$ At [26].

${ }^{81}$ At [40].

${ }^{82}$ At [73].

${ }^{83}$ At [73].

${ }^{84}$ At [73].

${ }^{85}$ Symbian Ltd v Comptroller General of Patents [2008] EWCA Civ 1066.

${ }^{86}$ At [59].
} 
The result in Symbian, as in Re IBM, is quite startling, for there is nothing present except software running on a computer, yet the difference between pure software and software "as such" turns on the effect it has on its enhanced running of the computer. The enhanced running of the computer is, technically, an improvement in one piece of software, the operating system, by another piece of software that links the DLLs used by the operating system and other programs. The decision in this case may be reconciled by viewing it as a special case dependant on the peculiar facts, namely the enhanced operation of DLLs. This special software is, practically, very different from other types of software, such as a word processing application. In that case, the contribution can be easily limited to the running of the program, with no increase in computer performance.

The special case in Symbian notwithstanding, the UK approach gives a narrower interpretation to the scope of patentability when compared to the European approach, a result which is distilled from the same statutory wording. The question remains, in light of the developments in case law and the interpretation of "as such", which approach a New Zealand court would prefer or look to in aiding the determination of the statutory meaning of the phrase.

\section{$F$ A New Zealand approach}

The case law in Europe and the UK shows differing results to the same question of interpretation. The divergence in interpretation of the words "as such" is testimony to the general lack of clarity attached to the phrase. Different tests are used which may produce different outcomes and as Jacob LJ noted, huge amounts of money may turn on this. ${ }^{87}$

The European approach is certainly friendlier towards the patenting of software, by taking a broad approach, but it is not necessarily good law. As indicated by Jacob LJ in Aerotel, the decisions of the EPO Boards of Appeal are mutually contradictory. ${ }^{88}$ Various cases are decided on very different grounds with his Lordship identifying at least four differing points of view. ${ }^{89}$ A lack of certainty makes the law difficult to predict and this can have the undesirable effect of raising the cost of doing business. Parliament's intention is to exclude the patentability of software, except for the embedded software carve-out, and to this end the European approach would fall well short of this.

\footnotetext{
${ }^{87}$ Aerotel, above n 77, at [24].

${ }^{88}$ At [25].

${ }^{89}$ At [25].
} 
The UK approach is a more restrictive one. Applying the four-step test to the facts in $R e$ IBM's Application would be likely to find that the exclusion clause applied as the actual contribution would fall solely in the excluded subject matter - the drawing of windows on a screen is an integral part of the operation of computer hardware. Additionally the contribution would not be technical beyond the mere fact of running a computer program. This may be problematic for applicants who apply for patents in both jurisdictions intellectual property rights appear stronger under the European approach. A more restrictive approach is consistent with the concern that greater patent protection was afforded in New Zealand compared to other countries. ${ }^{90}$ Interpreting "as such" in this way will ameliorate the disadvantage that New Zealand businesses might otherwise face from patents granted here but which relate to technology that is freely available elsewhere.

It is clear that the Select Committee wanted to exclude software patents from the Patents Bill by providing that "a computer program is not a patentable invention". 91 This points to a restrictive approach to the meaning of the phrase. The following supplementary order paper sought to give relief from the scope of the exclusion to New Zealand companies that had made significant investments in embedded software. This similarly points to a restrictive approach. It is unsustainable to suggest that Parliament would contemplate the state of affairs produced by EPO decisions such as the one in $\operatorname{Re} I B M$. Decisions such as that grant patents for what amounts to pure software and pure software should certainly fall well outside any exception intended by Parliament to cater for embedded software. However the decision in Symbian may also be said to grant a patent for pure software and so too is in opposition to Parliament's intent.

Courts do not just interpret for the instant case. They are mindful of the power of stare decisis and the desirability of a coherent body of law against which a person's affairs may be conducted. The UK courts have built up a consistent body of case law based around the application of an accepted test whilst the Boards of Appeal in Europe have not. This in itself does not point conclusively to an adoption of the UK approach, but the consistency found there is likely to be persuasive. New Zealand courts may be more likely to favour interpretations that are built upon the doctrine of precedent and that have developed a more workable body of case law. Adherence to consistent principle is more likely to yield consistency in the law.

\footnotetext{
${ }^{90}$ Patents Bill 2008 (235-1) (explanatory note) at 2.

${ }^{91}$ Patents Bill 2008 (235-2), cl 15(3A).
} 
The approaches taken abroad do not point emphatically in one direction over the other. In light of the commentary surrounding the Bill, a court would recognise the desire to place limits on the patentability of software. These limits should not exclude software altogether and should certainly not include it in its purest form. Of the two approaches, it is the UK approach that is more consistent with the intention of Parliament. A New Zealand court would prefer this approach over the European one.

\section{$V$ Analysis of the statutory interpretation of "as such" - Supplementary Order Paper No 237 - Amended Clause 10A}

A final change to the provisions relating to software was introduced in a further supplementary order paper which added significantly to the interpretation of Parliament's intent. $^{92}$ The new clause $10 \mathrm{~A}$ was modified and replaced with: ${ }^{93}$

10A Computer programs

(1) A computer program is not an invention and not a manner of manufacture for the purposes of this Act.

(2) Subsection (1) prevents anything from being an invention or manner of manufacture for the purposes of this Act only to the extent that a claim in a patent or an application relates to a computer program as such.

(3) A claim in a patent or an application relates to a computer program as such if the actual contribution made by the alleged invention lies solely in it being a computer program.

Subsection (2) is essentially the same and points to the same apportionment analysis, discussed previously, by using the words "to the extent that". The salient part is cl 10A(3). The wording is a statutory adoption of the four-step test laid down in Aerotel. Clause 10A(3) requires an identification of the "actual contribution". 94 This equates to step two of the Aerotel test, "identify the actual contribution". ${ }^{95}$ The next part of cl $10 \mathrm{~A}(3)$ requires an assessment to be made regarding whether that contribution "lies solely in it being a computer program." $" 96$ This is equivalent to step three in the Aerotel test. ${ }^{97}$ This adoption of the contribution approach is an endorsement of the Aerotel test

\footnotetext{
${ }^{92}$ Supplementary Order Paper 2012 (237) Patents Bill 2008 (235-2).

${ }^{93}$ At 1 .

${ }^{94}$ At 1 .

${ }^{95}$ Aerotel, above n 77, at [40].

${ }^{96}$ Supplementary Order Paper 2012 (237) Patents Bill 2008 (235-2) at 1.

${ }^{97}$ Aerotel, above n 77, at [40].
} 
and is the clearest indicator of Parliament's intent. The explanatory note states that "the provision does not include any consideration of whether the claim has a technical character or effect" $"$, which can be considered as a rejection of the European "technical effect" doctrine.

To aid the court in interpreting the provision two examples of processes that will and will not satisfy the clause are included. ${ }^{99}$ The examples are instantly recognisable. The first is a tailor made example constructed around a washing machine, in an obvious endorsement of the embedded software contained in Fisher \& Paykel's whiteware. The contribution is not limited to the instructions on the embedded chips, but is extended to include the effect that the improved motor control has on the efficiency of operation and cleanliness of the clothes. The legal test requires the determination of the actual contribution, but this may involve a consideration of the overall effect of the thing. Devices that employ embedded software will generally be able to make use of patent protection and firms will be able to bring other items, for example dishwashers or refrigerators, within the protection afforded by patents, with greater certainty and predictability.

The second example reuses the fact pattern from Macrossan's Application whilst simultaneously giving approval to the holding of the English Court of Appeal. ${ }^{100}$ The contribution in this case is said to lie solely within it being a computer program. The provision would most likely catch computer programs as in $\operatorname{Re} I B M$ as the windowing program in that case did not affect the computer itself. However the provision would most likely allow the patentability of an improved dynamically linked library, as in Symbian, since the actual contribution does not lie solely in it being a computer program but rather in the effect it has in enabling the computer to perform better.

The changes made are said to give the approach more consistency with New Zealand's international obligations, in particular the TRIPS ${ }^{101}$ agreement, and more consistency with English precedent which holds that patent protection is unavailable for inventions where the actual contribution lies solely in it being a computer program. ${ }^{102}$ Thus the wording of the provision and the explanatory note give the strongest indicator of

\footnotetext{
${ }^{98}$ Supplementary Order Paper 2012 (237) Patents Bill 2008 (235-2) (explanatory note) at 4.

${ }^{99}$ Supplementary Order Paper 2012 (237) Patents Bill 2008 (235-2) at 1-2.

${ }^{100}$ Aerotel, above n 77.

${ }^{101}$ Marrakesh Agreement Establishing the World Trade Organisation, 1867 UNTS 3, annex 1C (Agreement on Trade-Related Aspects of Intellectual Property Rights) (opened for signature 15 April 1994, entered into force 1 January 1995).

${ }^{102}$ Supplementary Order Paper 2012 (237) Patents Bill 2008 (235-2) (explanatory note) at 3.
} 
Parliament's intention. In less precise language then, software patentability will generally exist for inventions that use embedded software but will generally not be available for items of software alone. The rider to this is that there will still be exceptional circumstances where a piece of software will be patentable due to the contribution it makes to the computer upon which it runs.

Although Parliament is supreme and may in theory enact any legislation it wishes, countries do not exist in a vacuum. Nation states are subject to their obligations at international law. Domestic law then, should be consistent with the international instruments that nation states have subjected themselves to. To determine if this is so, the relevant provisions of the Patents Bill will be examined against the provisions in the TRIPS agreement.

\section{Consistency with the Agreement on Trade-Related Aspects of Intellectual Property Rights}

The Agreement on Trade-Related Aspects of Intellectual Property Rights (TRIPS) places limitations on patent law in New Zealand. The TRIPS Agreement is designed to give minimum standards of intellectual property protection to member states. However member states have a degree of autonomy over the mode of implementation at the domestic level and the extent of protection afforded over and above the minimum level. ${ }^{103}$ When constructing a statute, it is an established principle that it should be construed in accordance with international law. ${ }^{104}$ This requires a court to presume, when interpreting domestic legislation, that Parliament intended that legislation to be compatible with any applicable international law and to confer upon it a meaning that effects this consistency.

\section{A Is software technology?}

Article 27.1 states that "patents shall be available for any inventions...in all fields of technology". If software is regarded as a field of technology, or that software itself is technical, then it will be afforded patentability. The Patents Bill does not define software, indeed there is no mention of the word, nor does it define 'computer program'. Software or computer programs, then, are not defined as being technical under New Zealand law. On this ground, an exclusion from patentability is open to a member state. This

\footnotetext{
${ }^{103}$ Frankel, above n 1, at 31.

${ }^{104}$ Sellers v Maritime Safety Inspector [1999] 2 NZLR 44 (CA) at 57 per Keith J.
} 
conclusion is bolstered by the degree of autonomy that members have over implementation. It is open to members to determine the parameters under which software will be deemed to be technical and hence patentable.

This approach is supported by Article 10 which states that computer programs, in source or object code, will be protected as literary works. The implication here is that computer programs are not regarded as a field of technology, but rather as literary works and will therefore not be required to receive patent protection. Additionally, the suggestion is that had the TRIPS Agreement intended patent protection to be made available to computer software, in addition to copyright protection, it would have expressly said so. ${ }^{105}$ This argument is reinforced by the Copyright Act 1994, which protects computer programs as literary works. ${ }^{106}$

Finally it should be noted that the EPC already contains a computer software exclusion. ${ }^{107}$ This provision was in force prior to the entering into force of the TRIPS Agreement and the European Union was not required to reverse its exception. ${ }^{108}$

The software exclusion contained in the Patents Bill is not absolute. The preceding discussion shows that embedded applications as well as software that links DLLs will be patentable under New Zealand law. The conclusion is that this exclusion, centred on the contribution of the software, is not inconsistent with New Zealand's international obligations under the TRIPS Agreement - a New Zealand court will be able to interpret the provisions in a manner that is compatible with Article 27.1.

\section{Problems with the new Clause $10 \mathrm{~A}$}

The prevailing case law on point revolves around exceptionally fine distinctions of law that at times lacks consistency and clarity. Much of this is to do with the tension between the different strands of interpretation in the UK and Europe despite the near identity of the relevant legislation. However, the technical nature of the subject matter may also be responsible for a certain amount of obfuscation. For New Zealand purposes, the UK case law may be suitably developed for the most part, so that applicants may have some degree of confidence in what can and cannot be patented.

\footnotetext{
${ }^{105}$ Frankel, above n 1 , at 810 .

${ }^{106}$ Copyright Act 1994, ss 2, 14 and 16.

${ }^{107}$ Convention on the Grant of European Patents 1973, art 52.

${ }^{108}$ Frankel, above n 1, at 810 .
} 
It is trite to say that hard cases make bad law (the reverse may also be true) yet it is easy to entertain that thought here. Most of the decisions, while grappling with the application of the law to the facts, have seen the need to make distinctions based on the external effect, or the technical effect. ${ }^{109}$ Others give weight to a combination of hardware and software which together make a system. ${ }^{110}$ Yet others clothe their judgments with language that speaks of matters "of practical reality". ${ }^{111}$ What is apparent, is that the case law has had difficulty in advancing in any manner of elegance. There is no guarantee that the case law will be able to proceed on a smoother, more consistent path compared to the overseas experiences. Ultimately, as software and its application develop, so too may the ingenious arguments of counsel. However it must be noted that this is not a condition peculiar to this area of law alone, but rather one that is reflected in most areas as a consequence of the flux of daily life and endeavour.

\section{A Market incentives}

The law, through its regulation of human conduct, causes economic incentives in the marketplace. In tort law, the economic incentive to take reasonable care and the spreading of loss, promotes the insurance market. Patent law provides an incentive to publish in return for monopoly rights. The alternative is to keep things secret and in the absence of patent incentives, private research and development investment will be skewed towards technologies that can indeed be kept secret. ${ }^{112}$

Clause 10A incentivises embedded applications. Given the choice between two implementations, an inventor may be encouraged to choose the embedded option as this may, ceteris paribus, increase the likelihood of patent protection. These market signals may lead applicants to circumvent Parliament's intention by encapsulating algorithms and code that would otherwise by implemented in more conventional ways. This can increase the cost of doing business through the introduction of transaction costs relating to patent applications and extra costs associated with the embedded componentry. The increase in market inefficiency caused by a skewing towards embedded options, will ultimately be borne by the consumer.

\footnotetext{
${ }^{109}$ Re Vicom's Application [1987] T 208/84 (Official Journal of the European Patent Office).

110 Aerotel, above $\mathrm{n} 77$.

${ }^{111}$ Symbian Ltd v Comptroller General of Patents [2008] EWCA Civ 1066 at [59].

112 William van Caenegem Intellectual Property Law and Innovation (Cambridge University Press, Port Melbourne) at 8 .
} 
Intellectual property rights afforded to software patents may reduce efficiency even further by making products available at costs above marginal cost because they are protected from competition-by-imitation. ${ }^{113}$ Inventors that make strategic use of embedded applications are able to erect significant barriers to market entry thereby reducing competition and consumer choice whilst placing a premium on the value of the invention.

A normative analysis and thorough treatment of the market incentive and innovation debate surrounding patents is beyond the scope of this paper. However it is worth mentioning that open source programs have been written that add to the debate, with interesting results, by simulating the market interactions of inventors and competitors under patent and non-patent conditions. ${ }^{114}$

\section{B Distributed systems}

A distributed system may be defined as one that is comprised of several, or many components, spread across a geographical area. When operating properly together, they form a coherent, functioning system. The application of $\mathrm{cl} 10 \mathrm{~A}$ to these systems may produce inconsistencies.

Take as a simple example, a farming irrigation system. This system automatically moves the sprinklers, adjusts the water flow depending on the weather conditions, and records information pertaining to the amount of water used. This system could be implemented with embedded software located locally on the irrigation machinery. Under cl 10A(3), the actual contribution is the improved watering of the field, or perhaps, the more efficient production of crops. Patent protection may be afforded and enjoyed under cl 10A.

The same system could be implemented purely in software, on conventional hardware running on a server anywhere in the world and transmitting instructions across a wireless network. Once again parts of the system may not fall with the software exclusion but the status is not so clear. The disparate locations of the invention make it seem to be less of a coherent system. The separation of the processing from the physical actions also questions the extent to which a contribution lies solely in a computer program. Such a

\footnotetext{
${ }^{113}$ At 5 .

114 New Zealand Open Source Society "Submission on the Patent Bill 235-1 before the Commerce Committee" - Supplement 1.
} 
system would be more readily upgradeable and efficient as it is far easier to replace software on a server than it is to replace embedded chips.

The facts of this problem can be analogised to those in Aerotel. In that case the system was made of various components distributed across a physically connected network. Jacob LJ stated that the important point to note is that the system as a whole is new. ${ }^{115}$ On this footing then, a patent would be allowed for a distributed irrigation system. However, the complexity and interconnectedness of systems will only increase in the future. The number of components and the multiple roles they play in separate subsystems may not be so easily determined. It follows that it may be more difficult to determine the exact contribution made, and indeed which component of the system makes it, as devices may join and depart a system with greater frequency. However, the possibility of patent denial due to a lack of inventive step may mitigate this scenario.

\section{Conclusion}

The Patents Bill was introduced with the aim of modernising New Zealand's patent regime by encouraging innovation whilst balancing the interests of the public. The Bill introduced an exclusion for computer programs which excluded them from patentability to the extent that an application related to a computer program as such. This provision was enacted in the UK and Europe and was subsequently interpreted in different ways.

The statutory interpretation of this provision suggests that a New Zealand court would follow the narrower interpretation of patentability in the UK in preference to the wider interpretation in Europe. The European approach centred on the technical effect doctrine, would result in a lower patent threshold with more patent rights being granted in New Zealand compared to other countries. Parliament's intent is more closely aligned with the narrower approach. The acceptance of the contribution approach also provides more consistent results and proceeds on a more coherent body of case law. This interpretation is also consistent with New Zealand's obligations under international law as a signatory to the TRIPS Agreement.

Despite the increased clarity of the law, undesired economic results may arise. The law may encourage the development of embedded systems in favour of other approaches if inventors believe that monopoly rights can be achieved in this fashion. This may

$\overline{115}$ Aerotel, above n 77, at [52]. 
introduce market inefficiencies and have a chilling effect on innovation and competition. Distributed systems may also be problematic in the future, where the complexity of the system and its components cause difficulties in the determination of contribution. However these potential drawbacks are outweighed by the increased certainty of the law of software patents in New Zealand. An appropriate compromise has been struck in the law, one that protects the interests of New Zealand manufacturers whilst enabling software writers to innovate with little hindrance. 


\section{Bibliography}

A Cases

$1 \quad$ New Zealand

Frucor Beverages Ltd v Rio Beverages Ltd [2001] 2 NZLR 604 (CA).

Hughes Aircraft Application Patent Office, Patent Application Nos 221147, 233797 and 233798, 3 May 1995.

Sellers v Maritime Safety Inspector [1999] 2 NZLR 44 (CA).

$2 \quad$ Australia

IBM Corporation v Commissioner of Patents (1991) 22 IPR 417 (FCA).

$3 \quad$ England and Wales

Aerotel Ltd v Telco Holdings Ltd and Macrossan's Patent Application [2006] EWCA Civ 1371.

Symbian Ltd v Comptroller General of Patents [2008] EWCA Civ 1066.

$4 \quad$ Europe

Re IBM's Application [1999] RPC 861 (European Patent Office Technical Board of Appeal).

Re Vicom's Application [1987] T 208/84 (Official Journal of the European Patent Office).

\section{B Legislation \\ $1 \quad$ New Zealand}

Copyright Act 1994. 
Interpretation Act 1999.

Patents Act 1953.

Patents Act 2013.

Patents Bill 2008 (235-1).

Patents Bill 2008 (235-2).

Patents Bill 2008 (235-2) (select committee report).

Supplementary Order Paper 2012 (120) Patents Bill 2008 (235-2).

Supplementary Order Paper 2012 (237) Patents Bill 2008 (235-2).

$2 \quad$ United Kingdom

Patents Act 1977.

\section{Treaties and Conventions}

Convention on the Grant of European Patents 1973 (European Patent Convention).

Marrakesh Agreement Establishing the World Trade Organisation, 1867 UNTS 3, annex 1C (Agreement on Trade-Related Aspects of Intellectual Property Rights) (opened for signature 15 April 1994, entered into force 1 January 1995) (TRIPS).

\section{Books}

Concise Oxford English Dictionary (11 ${ }^{\text {th }}$ ed revised, 2009).

Susy Frankel Intellectual Property Law in New Zealand ( $2^{\text {nd }}$ ed, LexisNexis, Wellington, 2011).

Webster's New World Dictionary ( $3^{\text {rd }}$ college ed, 1991). 
William van Caenegem Intellectual Property Law and Innovation (Cambridge University Press, Port Melbourne).

\section{E Journal Articles}

Alfred P. Meijboom "New Developments Regarding the Patentability of SoftwareRelated Inventions in Europe" (1990) 72 JPTOS 583.

\section{F Parliamentary Materials}

InternetNZ "Submission to the Commerce Committee on the Patents Bill (235-1).

Fisher \& Paykel Appliances Limited "Submission on the Patents Bill 2009 to the Commerce Committee".

New Zealand Open Source Society "Submission on the Patent Bill 235-1 before the Commerce Committee".

New Zealand Open Source Society "Submission on the Patent Bill 235-1 before the Commerce Committee" - Supplement 1.

\section{G Papers and Reports}

Legislation Advisory Committee Guidelines on Process \& Content of Legislation (2000) at [3A.1.2].

The text of this paper (excluding title, abstract, contents, bibliography and footnotes) comprises approximately 8,000 words. 